\title{
Android Application for Product Enquiry and Navigation
}

\author{
Bhagirathi Bai V*, Gagan N Reddy, Hemanth N
}

Dept. of Mechatronics Engineering, Acharya Institute of Technology, Bengaluru, India

DOI: https://doi.org/10.21467/proceedings.1.52

* Corresponding author email: bhagirathistelkar@gmail.com

\begin{abstract}
This is an Android application developed for the purpose of product enquiry and navigation to the desired or nearest seller (generally a shopkeeper). The name/photo of the product needed by the user is uploaded and all the sellers within a certain radius or distance are notified with the name/photo of the product being enquired and later provide a feedback whether the product is available or not. If the feedback provided is positive, the location of the seller(s) is displayed on the user's map. If there are multiple sellers with the product available with them, the app navigates to the nearest seller from the user's live location. If the product isn't available with any of the sellers, the radius or distance for the enquiry can be increased seeking more options. In this way the user need not search every store physically resulting in saving time.

Keywords- Android Studio, Android Development, Source Code, XML, API, Google Maps, Geo-Location, Navigation.
\end{abstract}

\section{INTRODUCTION}

In this generation of advancement, tasks get simpler day to day. The simpler the things get, yet people run out of time. Certain tasks which sound simpler actually consumes more time and yet have to be simplified. By not ignoring the simpler tasks, this app-'FindForMe' comes into the making. As they say a solution can never be obtained unless one is encountered with a problem; the sprout for the application began when one of the author(s) had faced a problem in searching a product which was not likely to be available in regular e-commerce websites and not available in many local stores. It was a tough job to ask each Shopkeeper/Seller each time and be disappointed when one finds out that the product isn't available. To overcome this, ,FindForMe, was developed where a user who needs a product can place his enquiry on the application where all the sellers are notified with the user's need and a feedback whether the product is available or not. Wherein $\mathrm{n}$ number(s) of sellers with the product are displayed on the user's map and the user can make a choice to navigate to the nearest seller or the seller of his/her choice. The platform used to develop and test the application is Android Studio. The database for authentication and hosting is done using Google's Firebase. These are discussed in detail in the section 3.0.

(C) 2018 Copyright held by the author(s). Published by AIJR Publisher in Proceedings of the $3^{\text {rd }}$ National Conference on Image Processing, Computing, Communication, Networking and Data Analytics (NCICCNDA 2018), April 28, 2018.

This is an open access article under Creative Commons Attribution-NonCommercial 4.0 International (CC BY-NC 4.0) license, which permits any non-commercial use, distribution, adaptation, and reproduction in any medium, as long as the

AijR license, which permits any non-commercial use, distribution, 
Android Application for Product Enquiry and Navigation

\section{LITERATURE SURVEY}

Though the application may look simpler, it is distinct by its working from other similar apps. There are similar e-commerce[4] applications like bigbasket and groofers which search the product(s) in its respective database(s) servers and place the order and forward the details to the seller. There is no source of communication between the user and the seller(s). Infact, such applications don't show the location of seller(s) and can't navigate towards them. Products ordered on these app/website(s) can take day(s) to arrive. This app includes navigation of the user to the desired seller(s) which is of a new kind. Considering the fact that the seller needs to be educated about the app, we had conducted a survey regarding the number of seller(s) with a Smartphone at Bagalgunte, Bengaluru-560073. Out of 40 shopkeepers that we surveyed, surprisingly 34 sellers had a Smartphone with the necessary specifications[6]. This app could be useful for $83 \%$ of the sellers and later can expect even the remaining numbers to get educated about the app. We can see lot of things have changed in the past couple of years where a vegetable vendor uses UPI for transactions as they are educated about the app by word of mouth from person to person.

\subsection{THE PLATFORM, DATABASE, HOSTING AND TESTING Android Studio}

[2]Android Studio is the official Integrated Development Environment (IDE) which was developed by Jetbrainsfor Google's android system. The app is a replacement of the prior android's development platform- Eclipse Android Development Tools. Android studio was developed using JetBrains' Intellij IDEA software. It's founders are Google and Jetbrains. The platform has better user interface. The first version 0.1 was previewed from 16th May, 2013 at Google I/O conference. Later the version entered into beta-testing (version 0.8). Now the latest version available is Android Studio 3.2. Android Studio is a freeware and has source code (Fig 4.1) making it easier to code and accessing library functions without coding for every widget. Android Studio is supported on various platforms such as Windows, Linux and macOS. The version that we've used for the development of the application is Android Studio 3.1 which occupies a size of $683 \mathrm{Mb}$ (compressed zip file). In app downloads of SDK.NDK files can depend upon the requirements. It has Gradle-based built support, Lint tools to catch performance, layout editor which allows drag and drop. It supports linking the application with Google Cloud Platform and Firebase. It also supports all the programming languages of Intellij and PyCharm.

\section{Firebase}

[1]Firebase is yet another platform mobile and web application development, which was developed by Firebase Inc in 2011, and later bought by Google in 2014. The founders of the platform are James Tamplin and Andrew Lee. Firebase not only helps in Application development but also offers Cloud Messaging, Authentication services, Storage, Hosting, Database and many other services that we can find in the modern applications. We have used the Firebase's basic plan ie. Spark. It offers limited features than the paid version. Since the 
Application is for testing we haven't used the paid version. We only use it to store database of login credentials and authenticate through the app.

\section{DESIGN AND WORKING OF THE APPLICATION}

The initial page of the app (Fig 4.2) has to be a login page using the login activity or empty activity option on the new activity window of the editor. The Application uses a dark shade of blue for the background and a logo designed in .png format for the purpose of our app is displayed on the view using imageview source code. The language used here is XML. Later a button for the login has to be made which acts as a hyperlink to the authentication by Firebase, which has the entire database of login credentials.

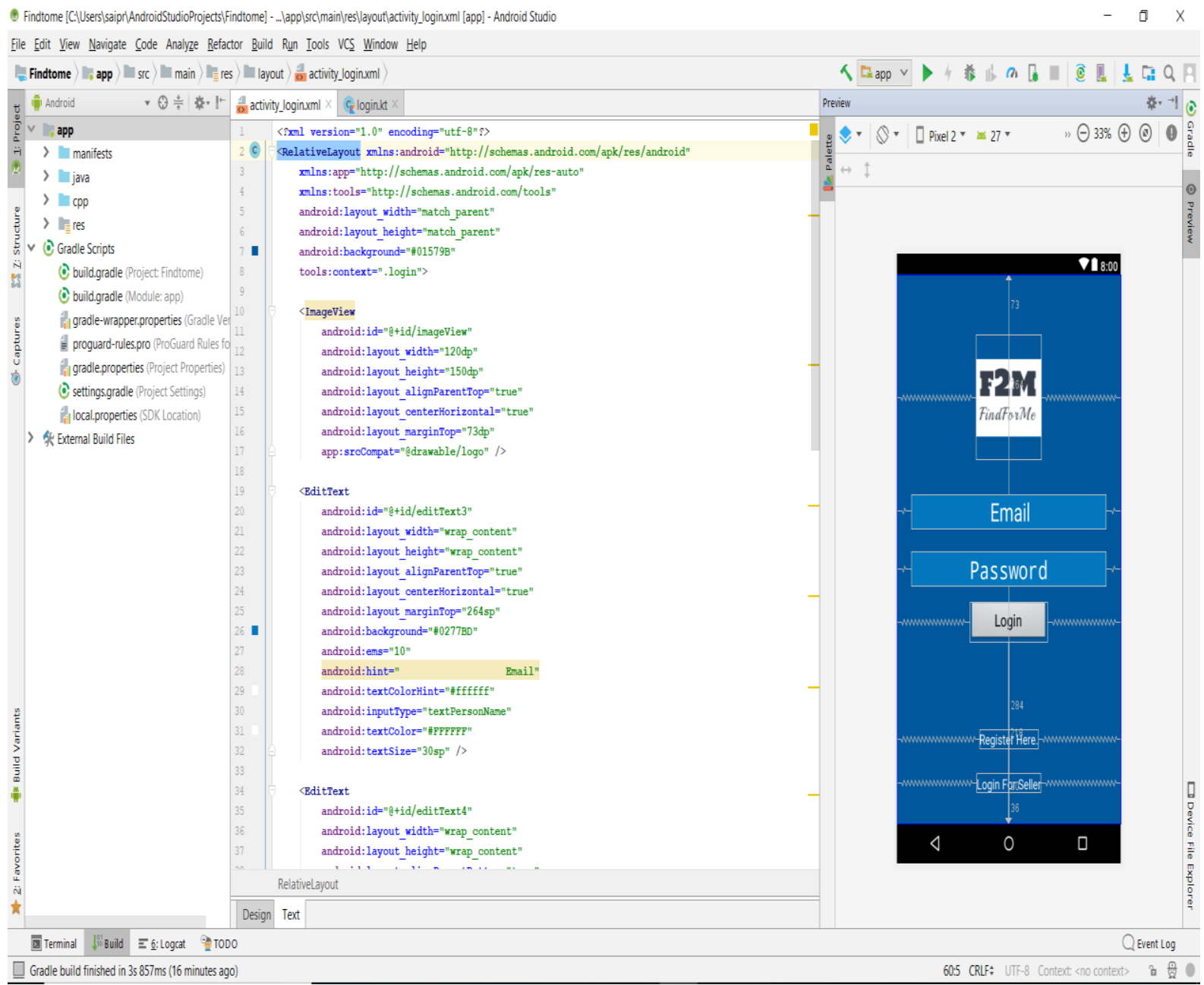

(Fig.4.1)

Proceedings of the $3^{\text {rd }}$ National Conference on Image Processing, Computing, Communication, Networking and Data Analytics (NCICCNDA 2018) 


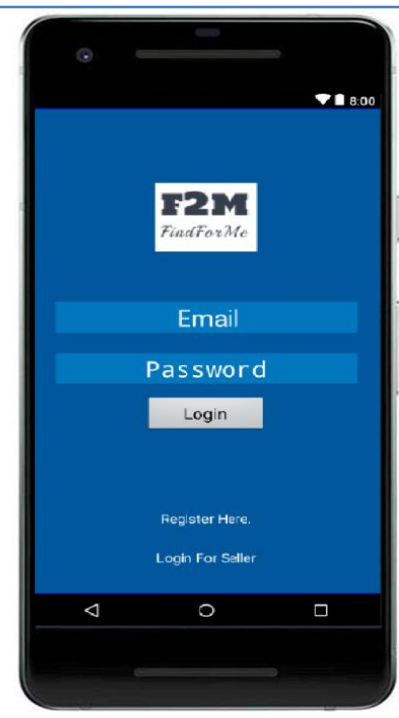

(Fig 4.2)

Once the authentication is successfully completed by Firebase, the user is directed to the next activity (Fig 4.3) where he/she will be asked to enter the name or upload the picture of the product to be searched. The seller(s) are notified with the name or picture as entered or uploaded by the user. The seller(s) within certain distance from the user is notified using firebase notification and combining with the conditional statement to get the distance between each seller and the user's live location.

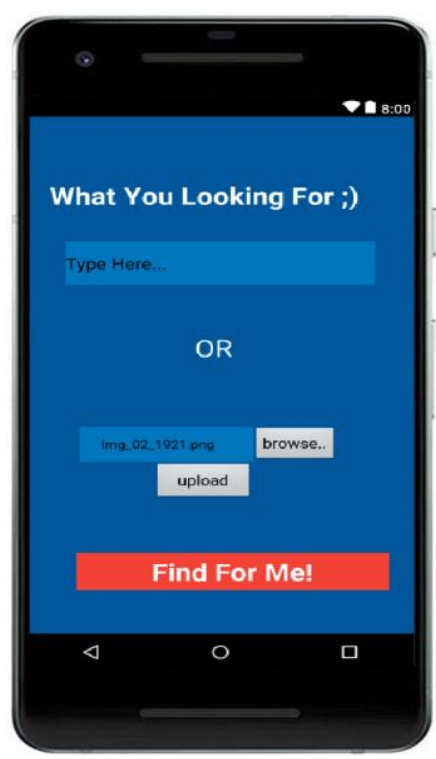

(Fig 4.3)

(User Interface for buyer) 


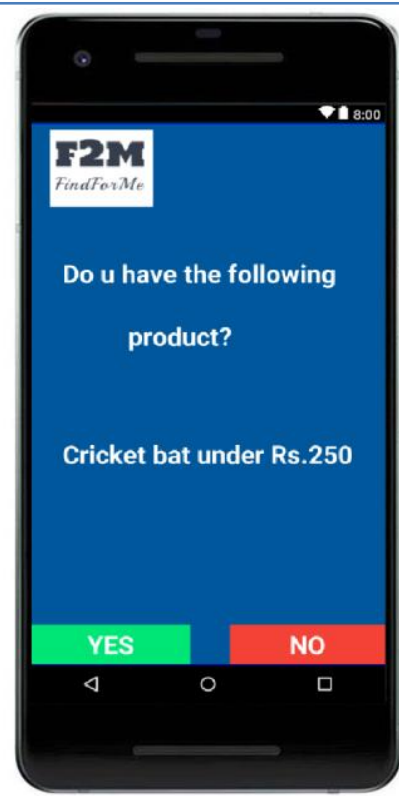

(Fig 4.4)

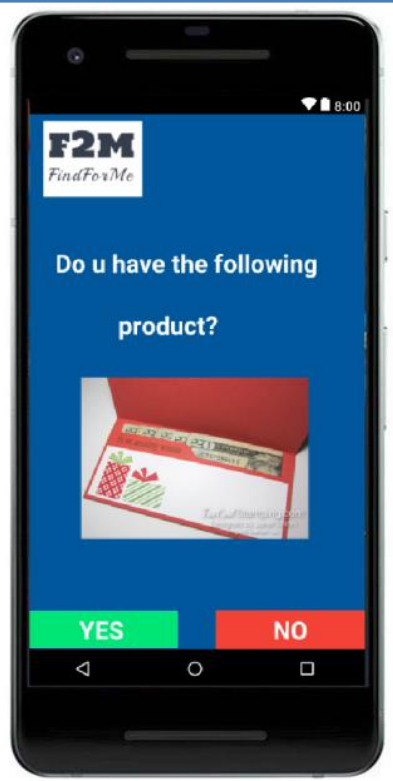

(Fig 4.5)

(User Interface for Seller)

Based on the feedback given by the seller(s), the user's map shows the location of the seller(s) who have provided a positive feedback and calculates the nearest seller using the distance between command which calculates the distance between two geometric coordinates (i.e. latitude and longitude). We build the activity as Location based activity which uses [3] Google Maps' API. The API key is unique and can be obtained by every Google user. The coordinates of the nearest seller is stored in the variable and later the app redirects directly to Google maps and navigates to the geometric coordinate stored in the variable (i.e. the coordinates of the nearest seller).

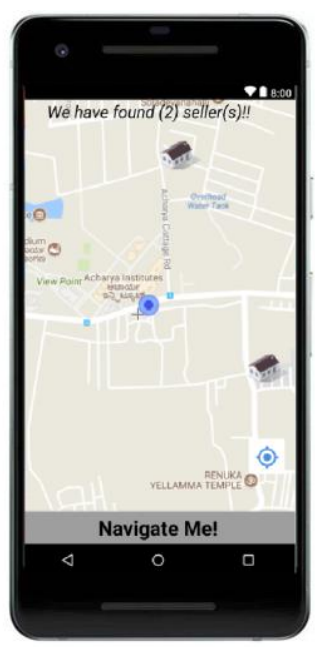

(Fig 4.6)

Proceedings of the $3^{\text {rd }}$ National Conference on Image Processing, Computing, Communication, Networking and Data Analytics (NCICCNDA 2018) 
Android Application for Product Enquiry and Navigation

4 FURTHER UPGRADES

The application is a basic version and can later find better updates like an option for language of choice, option to increase the radius or distance range for the product search, including a chat option between the user and seller, reviewing and reading the reviews of the sellers, include/build mobile wallet within the app for payments and improvement of location accuracy by various ways.

\section{CONCLUSION}

We all want to save time and make things simpler. Making the simplest things simpler might looks simple but, significant. Looking at the past years, the growth of new applications in the market and the number of people who use it are increasing extensively due to which certain applications which provide good user-interface and have high task ability are no doubt a good foundation for a software startup. By the app it is shown that the user can get the desired product hassle-free.

\section{References}

[1] Firebase- Study of Google Firebase API for Android-"Navdeep Singh"- International Journal of Innovative Research in Computer and Communication Engineering-Vol. 4, Issue 9, September 2016-pages16738-16743-ISSN(Online): 2320-9801.

[2] Android Studio- Android Mobile Application Build on Android studio-“R.Thamizharasi”- International Journal of Modern Computer Science (IJMCS)- Volume 4, Issue 1, February, 2016-pages1-4-ISSN: 2320-7868 (Online).

[3] Navigation reference- Android Navigation Application with Location-Based Augmented Reality-“Nyoman Piarsa”“Putu Wira Buana”““ Gede Agus Mahasadhu”- IJCSI International Journal of Computer Science Issues- Volume 13, Issue 4, July 2016-pages83-89- | ISSN (Online): 1694-0784.

[4] Ecommerce-E-COMMERCE AND IT IMPACTS ON GLOBAL TREND AND MARKET -"Shahrzad Shahriari”“ Mohammadreza Shahriari”-“ Saeid gheiji”- INTERNATIONAL JOURNAL of RESEARCH GRANTHAALAYAH-Vol.3(Iss.4):April,2015-pages49-55-ISSN- 2350-0530(O).

[5] Online shooping- Donthu, N.; Garcia, A., "The Internet shopper”, Journal of Advertising Research, Vol. 39, No. 3, pp. 52-58, 1999.

[6] Smartphone users survey-A STUDY ON MOBILE USAGE AND DATA PENETRATION IN INDIA USING PREDICTIVE ANALYTICS-“DishaRajkumar”-“Sharmila K”“"SanthoshRebello”- International Journal of Latest Trends in Engineering and Technology-Special Issue SACAIM 2016, pp. 260-265-e-ISSN:2278-621X. 